\title{
An empirical study on the influence of patents on the management performance of corporates
}

\author{
Changyong Yang, Ph.D. student, Dept. Of Knowledge Service \& Consulting, Hansung University, Seoul, Korea \\ dreamer0401@hanmail.net \\ *Jung-Wan Hong, Professor, Dept. Of Knowledge Service \& Consulting, Hansung University, Seoul, Korea, \\ jwhong@hansung.ac.kr \\ Yen-Yoo You, Professor, Dept. Of Knowledge Service \& Consulting, Hansung University, Seoul, Korea, \\ threey0818@hansung.ac.kr3 \\ *Corresponding Author
}

\begin{abstract}
Background/Objectives: We would like to study empirically on the impact of the quantitative and qualitative aspects of patent rights on management performance on small and medium-sized enterprises that did not have much research due to lack of data. We want to examine whether the growth rate of sales in the management performance of small and medium enterprises after securing patent rights is different from that of general small and medium enterprises.

Methods/Statistical analysis: We would like to analyze whether small and medium-sized enterprises that hold patents show an average sales growth rate of $9 \%$ or more, more than double the average sales growth rate of all small and medium-sized enterprises. In 2012, 278 small and medium-sized manufacturing companies with patents that took out loans through guarantees from the Korea Credit Guarantee Fund were selected as samples. The relationship between the average sales growth rate of these companies over the next five years and the quantitative and qualitative value of patents was analyze.

Findings: Both independent variables(the number of patents, the average score of patents) were significant for distinguishing between corporates with an average growth in sales more than twice that of general small and medium-sized enterprises and those with less than twice the average sales growth rate. In this case, 'the average score of patents' of the two variables was found to be more important, and the discriminant power was greater. it can be said that the discriminant power is useful in order of 'average score of patents', 'number of patents'.

Improvements/Applications: In previous research, large companies were analyzed to focus on their past management performance and patent rights. In this study, it is meaningful that we looked at the variability in future sales of small and medium-sized enterprises with patents through empirical analysis. There are limitations that only average sales growth rate was used as a variable among indicators of a corporate's management performance in this study.
\end{abstract}

Keywords: Classification function, Discriminant analysis, Hit ratio, Patent, Sales growth rate, Smal 1 and medium-sized enterprise.

$\begin{array}{lll}\text { Received: 09.12.2020 } & \text { Accepted: 16.01.2021 } & \text { Published: 05.02.2021 }\end{array}$

\section{INTRODUCTION}

Our society is now undergoing rapid changes more than ever before. In the past, if the industrial revolution has greatly improved the productivity of the physical workforce, now is an era in which how much differentiating product development, production, service and distribution by creating, accumulating and utilizing knowledge determines competitiveness. Since the 1990s, countries around the world have actively studied knowledge-based economy, making it the most important topic of the 21st century. As the transition to this knowledge-based economy accelerates, the role of intellectual property as a key component of corporate survival and competitiveness and the importance of intellectual property activities are emphasized[1]. Entering the so-called Fourth Industrial Revolution, the importance of securing and protecting intellectual property rights is further emphasized. The trade war between the U.S. and China also has its essence in protecting intellectual property rights.

Especially in small and medium-sized enterprises, the role of patent rights is more meaningful than that of large corporations. Small and medium-sized enterprises make up $99 \%$ of all enterprises, and $83 \%$ of all workers work for small and medium-sized enterprises, so the status of small and medium-sized 
enterprises is large enough to be large in the national economy[2]. However, it is true that there are limitations for small and medium-sized enterprises in many aspects, such as capital and sales networks, to compete with large companies. However, since patents, which are intellectual property, compete with innovation and ideas regardless of the size of capital or the size of enterprise, small and medium-sized enterprises can compete with large companies in this field. For this reason, it is believed that the activities to secure intellectual property are meaningful for small and medium-sized enterprises.

With its importance highlighted, intellectual property rights are increasing quantitatively in Korea, but in terms of their usability, they are showing a decreasing trend. Therefore, we would like to examine the impact of patents, which are representative intellectual property rights, on corporate performance. In particular, we would like to study empirically on the impact of the quantitative and qualitative aspects of patent rights on management performance on small and medium-sized enterprises that did not have much research due to lack of data [11-27]. We would like to examine whether the growth rate of sales in the management performance of small and medium enterprises after securing patent rights is different from that of general small and medium enterprises. Due to the lack of manpower, the activities to secure intellectual property rights in small and medium-sized enterprises hinder normal sales activities, resulting in a decrease in sales growth or a tendency for many companies to stay at the current level. In corporate credit screening, external growth, such as corporate sales, is considered, but in this regard, small and medium-sized companies engaged in patent-related activities, are at a disadvantage. Therefore, we would like to analyze how the increase in sales after securing patent rights is distinguished from other corporates in general, instead of focusing on the corporate's past management performance and relationship. This will provide information to corporate stakeholders on how patents affect indicators related to the company's future growth potential so that they can be used for loan screening or guarantee screening.

\section{Related Works}

\subsection{Preceding studies in foreign country}

Looking at the preceding study on the management performance of companies based on patent activities, 365 out of Fortune 500 companies in the U.S. were selected and the effects of patent registrations on revenue, sales growth and profit rates were researched. It has been confirmed that the number of patent registrations has a positive relationship with sales growth rate and that there is a positive impact on profits from the increase in sales[3].

In addition, an analysis of 57 pharmaceutical companies in the United States confirmed that both the number of patent applications and that of patent registrations had an impact on sales, and in particular, the number of patent applications was confirmed to have a greater impact on sales[4].

In the case of Germany, 50 manufacturers of electric tools were analyzed and the study looked at the relationship between corporate performance in two aspects: "patent activity" and "quality level of patent technology" of corporates. The relationship between two variables was verified and found to be highly correlated, with the corporate's performance index (average sales growth rate, sales per employee, etc.) as dependent variables and the patent index (number of patent applications, number of patent applications per employee, effective patent ratio, etc.) as independent variables[5].

\subsection{Preceding studies in Korea}

In one study, 89 out of the top 150 patent-registered companies from 1998 to 2002 were sampled and analyzed empirically. The number of patent applications affected the growth of the corporate, and the number of patent applications per employee was analyzed as having an impact on productivity, indicating that the quantitative aspect of the patent was a significant variable in the corporate's performance[6].

In a study of 62 general corporates and 38 venture firms, regression analysis confirmed that the number of patent registrations had a significant effect on sales and net profit margins [7].

A researcher sampled 200 venture companies based on sales at the end of 2008. Based on the rating data of the patent evaluation system, the quality level was assigned, and the analysis revealed that the quality level had a significant relationship with sales and net profit[8].

In another study, researcher analyzed how the quantitative and qualitative value of patents affected corporate performance. In this study, the quantitative value of patents did not have any special impact on the corporate's management performance, but qualitative value was analyzed as having a positive relationship with increased sales[9]. 


\section{Materials and Methods}

\subsection{Selecting of sample company}

Most preceding studies targeted larger companies than small and medium-sized enterprises, and the number of samples was small because of the restriction of data. In addition, the focus was on the correlation between patents and corporate management performance through regression analysis based on past financial data to analyze the impact of patent rights on management performance. In this study, we analyzed the relationship between patents held by small and medium-sized enterprises, which play a big role in the national economy, and future business performance. To this end, the analysis was conducted on non-listed small and medium-sized enterprises with patents that received loans through the guarantee of the Korea Credit Guarantee Fund. The impact of patents on management performance may vary depending on the industry and may result in distorted results, so only corporates that operate manufacturing are sampled.

\subsection{Selecting variables}

As independent variables, the quantitative value of patents and the qualitative value of patents that were widely used in prior research were used. The quantitative value means the number of patents owned by the company and utilizes the number of valid patent registrations. Because of the characteristics of small and medium-sized enterprises, almost all of them hold fewer than 10 patents. Therefore, the distribution of patents has left-leaning skewness and high kurtosis, so the number of patents has been replaced by natural logarithmic values. Among other independent variables, the qualitative value of a patent refers to the qualitative level of a patent. In this study, SMART3 (System to Measure, Analyze and Rate patent Technology 3) score, a patent-specific rating data of the patent evaluation system built by Korea Invention Promotion Association with the Korean Intellectual Property Office, was used as the quality value of patents. In other words, the qualitative value was used to average patent score divided by the number of patents of the total SMART3 score.

Among the various indicators of a corporate's management performance, the dependent variable was selected as the average sales growth rate, which was analyzed to be mostly related to patents in the preceding studies.

In 2012, 278 small and medium-sized manufacturing companies with patents that took out loans through guarantees from the Korea Credit Guarantee Fund were selected as samples. The relationship between the average sales growth rate of these companies over the next five years and the quantitative and qualitative value of patents was analyzed.

\section{Empirical analysis}

\subsection{Research project}

Average sales growth rate for small and medium-sized enterprises from 2012 to 2016 is $4.28 \%$. Therefore, we would like to analyze whether small and medium-sized enterprises that hold patents show an average sales growth rate of $9 \%$ or more, more than double the average sales growth rate of all small and medium-sized enterprises. In other words, through a discriminant analysis using the statistical program SPSS22, we will examine whether the quantitative value of a patent, 'the number of patents', and the qualitative value of a patent, 'the average score of patents', are useful in distinguishing between less than $9 \%$ increase in average sales and more. Also, we would like to examine which independent variables have significant discriminant power, and which independent variables have great discriminant power.

\subsection{Statistical analysis}

Table 1 shows the mean and standard deviation of two independent variables in two groups. Both the two variables, 'number of patents LN' and 'average score of patents', were higher than group 1 (a group whose average sales growth rate is less than 9\%) in group 2(a group with an average sales growth rate of $9 \%$ or more).

Table1 Group Statistics

\begin{tabular}{|c|c|c|c|c|}
\hline \multirow[b]{2}{*}{ Classifying } & \multirow[b]{2}{*}{ Mean } & \multirow[b]{2}{*}{ Std. Deviation } & \multicolumn{2}{|c|}{ Valid N (listwise) } \\
\hline & & & Unweighted & Weighted \\
\hline Group 1 Number of patents LN* & .888 & .8394 & 126 & 126.000 \\
\hline
\end{tabular}




\begin{tabular}{|c|c|c|c|c|c|}
\hline & Average score of patents & 67.370 & 2.6729 & 126 & 126.000 \\
\hline \multirow[t]{2}{*}{ Group 2} & Number of patents LN & 1.288 & 1.0538 & 152 & 152.000 \\
\hline & Average score of patents & 69.702 & 2.6221 & 152 & 152.000 \\
\hline \multirow[t]{2}{*}{ Total } & Number of patents LN & 1.107 & .9813 & 278 & 278.000 \\
\hline & Average score of patents & 68.645 & 2.8852 & 278 & 278.000 \\
\hline
\end{tabular}

* Natural logarithmic value

Table 2 shows results of ANOVA. As a result of the difference verification, the difference in 'the number of patents LN' and 'the average score of patents' between the two groups was significant. Where Wilks' lambda is the ratio of 'intra-group variance / (intra-group variance + inter-group variance)' and the greater 'inter-group variance' compared to 'intra-group variance', the closer it is to zero and vice versa, to 1. It has the opposite direction to the F value in ANOVA. Of the two variables, Wilks' lambda of the average score of patents is small and the $\mathrm{F}$ value is large. It can be said that the average score of patents means a high determinant power. That is to say, the difference between two groups means that the average score of patents is the largest.

Table2 Tests of Equality for Group Means

\begin{tabular}{|l|l|l|l|l|l|}
\hline & Wilks' Lambda & F & df1 & df2 & Sig. \\
\hline Number of patents LN & .959 & 11.890 & 1 & 276 & .001 \\
Average score of patents & .838 & 53.546 & 1 & 276 & .000 \\
\hline
\end{tabular}

Table 3 represents the covariance matrix of the groups that are classified respectively.

Table3 Covariance Matrices

\begin{tabular}{|ll|l|l|}
\hline classifying & Number of patents LN & Average score of patents \\
\hline Group 1 & Number of patents LN & .705 & -.205 \\
& Average score of patents & -.205 & 7.144 \\
\hline \multirow{3}{*}{ Group 2 } & Number of patents LN & 1.110 & -.492 \\
\cline { 2 - 5 } & Average score of patents & -.492 & 6.875 \\
\hline \multirow{2}{*}{ Total } & Number of patents LN & .963 & -.129 \\
\cline { 2 - 4 } & Average score of patents & -.129 & 8.324 \\
\hline
\end{tabular}

Table 4 shows the results of the verifying of the assumption of equality in the covariance matrix. Box's $M$ verification results show no violation of the assumption(Box's $M=7.248, p=0.066$ ).

Table4 Test Results

\begin{tabular}{|ll|l|}
\hline Box's M & & 7.248 \\
F & Approx. & 2.397 \\
& $\mathrm{df1}$ & 3 \\
\cline { 2 - 3 } & $\mathrm{df2}$ & 106384207.576 \\
\cline { 2 - 3 } & Sig. & .066 \\
\hline
\end{tabular}

Table 5 provides information on canonical discriminant function. This shows Wilks' lambda and $\chi^{2}$ 
verification results. $\chi^{2}$ verification confirms that there are differences between two groups across independent variables, and the null hypothesis $\left(\mathrm{H}_{0}\right)$ is as below.

$\mathrm{H}_{0}$ : The means of all independent variables are the same among groups.

The results of the verification showed significantly $(p=0.000)$. Two independent variables can be said to be significant in separating the group with an average sales growth rate of $9 \%$ or more and a group of less than $9 \%$ in combination.

Table5 Wilks' Lambda

\begin{tabular}{|l|l|l|l|l|}
\hline Test of Function(s) & Wilks' Lambda & Chi-square & df & Sig. \\
\hline 1 & .788 & 65.403 & 2 & .000 \\
\hline
\end{tabular}

Table 6 shows standardized canonical discriminant function coefficients. This coefficient of standardization shows the relative importance of the two variables in describing a group of corporates with an average sales growth rate of $9 \%$ or more and less than $9 \%$. In this case, 'the average score of patents' of the two variables was found to be more important, and the discriminant power was greater.

Table6 Standardized Canonical Discriminant Function Coefficients

\begin{tabular}{|l|l|}
\hline \multirow{2}{*}{} & Function \\
\cline { 2 - 2 } & 1 \\
\hline Number of patents LN & .532 \\
\hline Average score of patents & .926 \\
\hline
\end{tabular}

Table 7 describes the structure matrix. The structure matrix shows the correlation between each variables and the standardized canonical discriminant function. Here again, the correlation between the average score of patents and the discriminant function was higher. Discriminant loading is usually significant if it is \pm 0.40 or higher[10]. Therefore, it can be said that the discriminant power is useful in order of 'average score of patents', 'number of patents LN'.

Table7 Structure Matrix

\begin{tabular}{|l|l|}
\hline & Function \\
\cline { 2 - 2 } & 1 \\
\hline Average score of patents & .850 \\
\hline Number of patents LN & .401 \\
\hline
\end{tabular}

Table 8 shows classification function coefficients, which can be used to derive classification functions between groups.

Classification function of group 1

$=4.816 * \mathrm{X}_{1}+9.877 * \mathrm{X}_{2}-335.552$

Classification function of group 2

$=5.389 * \mathrm{X}_{1}+10.240 * \mathrm{X}_{2}-361.050$

Group 1: a group with an average sales growth rate of less than $9 \%$

Group 2: a group with an average sales growth rate of $9 \%$ or more

$\mathrm{X}_{1}$ : number of patents $\mathrm{LN}, \mathrm{X}_{2}$ : average score of patents

The above two classification functions allow us to predict which group to belong to and are classified into groups that appear to be large values by inserting the value of variables in the classification function[2]. 
Table8 Classification Function Coefficients (Fisher's linear discriminant functions)

\begin{tabular}{|l|l|l|}
\hline \multirow{2}{*}{} & \multicolumn{2}{|l|}{ Classification } \\
\cline { 2 - 3 } & Group 1 & Group 2 \\
\hline Number of patents LN & 4.816 & 5.389 \\
\hline Average score of patents & 9.877 & 10.240 \\
\hline (Constant) & -335.552 & -361.050 \\
\hline
\end{tabular}

Table 9 explains how accurately the classification function predicts 278 corporates analyzed statistically. 89 out of 126 corporates with an average sales growth rate of less than $9 \%$ and 107 out of 152 corporates with an average sales growth rate of more than 9\% were correctly classified. Overall, 196 of the 278 are correctly classified with a hit ratio of $70.5 \%$.

Table9 Classification Results

\begin{tabular}{|ll|l|l|l|}
\hline \multirow{2}{*}{ Classification } & \multicolumn{2}{|l|}{ Predicted Group Membership } & \multirow{2}{*}{} \\
\cline { 3 - 5 } & & Group 1 & Group 2 & Total \\
\hline Original Count & Group 1 & 89 & 37 & 126 \\
\cline { 2 - 5 } & Group 2 & 45 & 107 & 152 \\
\hline & Group 1 & 70.6 & 29.4 & 100.0 \\
\cline { 2 - 5 } & Group 2 & 29.6 & 70.4 & 100.0 \\
\hline
\end{tabular}

\section{Conclusion}

In this study, we looked at how the quantitative and qualitative value of patent rights, which are intellectual property rights, affect corporate management performance. An empirical analysis was conducted using 'the number of patents' as the quantitative value of patents, 'the average score of patents' as the qualitative value of patents, and the average sales growth rate as a corporate management performance. As a result, both independent variables used in this study were significant for distinguishing between corporates with an average growth in sales more than twice that of general small and mediumsized enterprises and those with less than twice the average sales growth rate.

In previous research, large companies were analyzed to focus on their past management performance and patent rights. In this study, it is meaningful that we looked at the variability in future sales of small and medium-sized enterprises with patents through empirical analysis. It is also meaningful that the research model provided the framework for the analysis of future sales growth for small and mediumsized enterprises with patents during the credit screening process.

In this study, there are limitations that only average sales growth rate was used as a variable among indicators of a corporate's management performance. It is necessary to analyze a corporate's management performance by utilizing indicators that represent its earnings, such as its operating profit.

\section{Acknowledgment}

This research was financially supported by Hansung University.

\section{References}

[1] Kim SC, Kang SM. The study of an analysis on patent management affecting the company performance. Journal of Korea Technology Innovation Society. 2008;11(2):171-93. Available from: http://www.dbpia.co.kr/Journal/articleDetail?nodeId=NODE01213376\#none 
[2] Yang CY, You YY. An empirical study on the default prediction model in small and medium-sized enterprises using financial ratios. Research in World Economy. 2020;11(2): 129-35. DOI:10.5430/rwe.v11n2p129.

[3] Scherer FM. Corporate inventive output, profit and growth. Journal of Political Economy. 1965;73(3):290-97.

[4] Comanor WS, Scherer FM. Patents statistics as a measure of technology change. Journal Political Economy. 1969;77(3):392-98.

[5] Ernst H. Patenting strategies in the German mechanical engineering industry and their relationship to company performance. Technovation. 1995;15(4):225-40.

[6] Oh JY. An analysis on factor of company's industrial property right affecting the company's development [master's thesis]. South Korea: Yonsei University; 2003. Available from: http://www.riss.kr/link?id=T8964313

[7] Lee KH, Yoon BS. The effects of Patents on firm value. Journal of Technology Innovation. 2006;14(1): 67-99. Available from: http://www.papersearch.net/thesis/article.asp?key=2729494

[8] Ahn YS. An empirical analysis about the effect on performance of firm's patent competency. Knowledge Management Research. 2010;11(1):83-96. Available from: http://kiss.kstudy.com/thesis/thesis-view.asp?key=2844209

[9] Jung KH. A study on the effect of the value of patents on business performance [master's thesis]. South Korea: Seoul National University; 2019. Available from: http://sspace.snu.ac.kr/handle/10371/161746

[10] Hair JF, Black WC, Babin BJ, Anderson RE. Multivariate data analysis. 7th ed. Pearson; 2010. p. 309.

[11] Bhoi, A. K., Sherpa, K. S., \& Khandelwal, B. (2018). Arrhythmia and ischemia classification and clustering using QRS-ST-T (QT) analysis of electrocardiogram. Cluster Computing, 21(1), 1033-1044.

[12] Reddy, A. V., Krishna, C. P., \& Mallick, P. K. (2019). An image classification framework exploring the capabilities of extreme learning machines and artificial bee colony. Neural Computing and Applications, 1-21.

[13] Bisoy, S. K., Mallick, P. K., \& Mishra, A. Fairness Analysis of TCP Variants in Asymmetric Network. International Journal of Engineering \& Technology, 7(2.12), 231-233.

[14] Mallick, P. K., Mishra, D., Patnaik, S., \& Shaw, K. (2016). A semi-supervised rough set and random forest approach for pattern classification of gene expression data. International Journal of Reasoningbased Intelligent Systems, 8(3-4), 155-167.

[15] Mallick, P. K., Mohanty, B. P., \& Jha, S. A novel approach using. Supervised and Unsupervised Learning" to prevent the adequacy of Intrusion Detection Systems", International Journal of Engineering \& Technology, 7(3.34), 474-479.

[16] Satapathy, S. K., Mishra, S., Sundeep, R. S., Teja, U. S. R., Mallick, P. K., Shruti, M., \& Shravya, K. (2019). Deep learning based image recognition for vehicle number information. International Journal of Innovative Technology and Exploring Engineering, 8, 52-55.

[17] Mallick, P. K., Kar, S. K., Mohanty, M. N., \& Kumar, S. S. (2015). Use of histogram approach in color band detection for electrical passive component. International Journal of Applied Engineering Research, 10(44), 31446-31450.

[18] Mishra, S., Mallick, P. K., Tripathy, H. K., Bhoi, A. K., \& González-Briones, A. (2020). Performance Evaluation of a Proposed Machine Learning Model for Chronic Disease Datasets Using an Integrated Attribute Evaluator and an Improved Decision Tree Classifier. Applied Sciences, 10(22), 8137.

[19] Bhoi, A. K., Sherpa, K. S., \& Mallick, P. K. (2014, April). A comparative analysis of neuropathic and healthy EMG signal using PSD. In 2014 International Conference on Communication and Signal Processing (pp. 1375-1379). IEEE.

[20] Bhoi, A. K., Sherpa, K. S., Khandelwal, B., \& Mallick, P. K. (2019). T Wave Analysis: Potential Marker of Arrhythmia and Ischemia Detection-A Review. In Cognitive Informatics and Soft Computing (pp. 121130). Springer, Singapore.

[21] Mishra, S., Mallick, P. K., Jena, L., \& Chae, G. S. (2020). Optimization of Skewed Data Using SamplingBased Preprocessing Approach. Frontiers in Public Health, 8.

[22] Bhoi, A. K., \& Sherpa, K. S. (2016). Statistical analysis of QRS-complex to evaluate the QR versus RS interval alteration during ischemia. Journal of Medical Imaging and Health Informatics, 6(1), 210-214.

[23] Mishra, S., Tripathy, H. K., Mallick, P. K., Bhoi, A. K., \& Barsocchi, P. (2020). EAGA-MLP-An Enhanced and Adaptive Hybrid Classification Model for Diabetes Diagnosis. Sensors, 20(14), 4036.

[24] Bhoi, A. K., Mallick, P. K., Liu, C. M., \& Balas, V. E (Eds.) (2021). Bio-inspired Neurocomputing, Springer.

[25] Oniani, S., Marques, G., Barnovi, S., Pires, I. M., \& Bhoi, A. K. (2020). Artificial Intelligence for Internet of Things and Enhanced Medical Systems. In Bio-inspired Neurocomputing (pp. 43-59). Springer, Singapore. 
[26] Marques, G., Bhoi, A.K., Albuquerque, V.H.C. de, K.S., H. (Eds.) (2021). IoT in Healthcare and Ambient Assisted Living, Springer

[27] Marques, G., Miranda, N., Kumar Bhoi, A., Garcia-Zapirain, B., Hamrioui, S., \& de la Torre Díez, I. (2020). Internet of Things and Enhanced Living Environments: Measuring and Mapping Air Quality Using Cyber-physical Systems and Mobile Computing Technologies. Sensors, 20(3), 720. 